\title{
Preparation of Hybrid Materials Containing M(II)Pc (M = Fe, Co, Ni)/Nylon films with Optical and Electrical Properties
}

\author{
María Elena Sánchez Vergara1, Mariana Huerta-Francos' ${ }^{1}$, Mariluz Menéndez-Huerta1, \\ Mercedes Espinosa-Creel1, Oscar Amelines-Sarria², Jaime Santoyo-Salazar ${ }^{3}$ \\ ${ }^{1}$ College of Engineering, Universidad Anáhuac México Norte, Huixquilucan, México \\ ${ }^{2}$ Physics Institute, Department of Condensed Material, Universidad Nacional Autónoma de México, Coyoacán, \\ México \\ ${ }^{3}$ Physics Department, Research and Advanced Studies Center of the National Polythechnic Institute \\ (CINVESTAV-IPN), Zacatenco, México \\ Email: elena.sanchez@anahuac.mx
}

Received 10 June 2015; accepted 28 July 2015; published 31 July 2015

Copyright (C) 2015 by authors and Scientific Research Publishing Inc.

This work is licensed under the Creative Commons Attribution International License (CC BY).

http://creativecommons.org/licenses/by/4.0/

(c) (i) Open Access

\section{Abstract}

Hybrid materials consisting of M(II)Pc (M = Fe, Co, Ni) particles dispersed in nylon 11 films have been prepared by using a thermal relaxation technique. The obtained films are characterized by AFM, SEM and TEM, and their structural composition is determined by IR spectroscopy and EDS. The M(II)Pc particles are homogeneously distributed in the nylon 11 matrix after heat treatment. Optical absorption studies of the hybrid films are performed in the $200-1150 \mathrm{~nm}$ wavelength range. The band-model theory is applied to determine the optical parameters for MPc/nylon 11 hybrid films. The optical band gap of the thin films is determined from the $(\alpha h v)^{1 / 2} v s$. $h v$ plots for indirectly allowing transitions and comparing with the as-deposited M(II)Pc thin films. The values of the optical band gap calculated from the absorption spectra, range between 1.07 and $2.7 \mathrm{eV}$. The electrical conductivity is measured in order to evaluate the conductivity behavior of these hybrid films.

\section{Keywords}

Metallophthalocyanines, Thermal Relaxation, Polymer Film, Optical Band Gap, Electrical Properties

\section{Introduction}

Optical properties of composites thin films consisting of nanometer-sized semiconductor particles dispersed in 
solid dielectric materials, such as polymers, have been of increasing interest for practical reasons, largely because of their novel applications as photonics and electronics devices based on quantum size effects [1] [2]. However, most of the composites thin films studied to date have been inorganic compounds such as metals [1]-[3]. In the case of organic materials, there has been little research conducted so far due to difficulties associated with preparation and characterization [4]. Recently, various techniques to fabricate such composite or hybrid thin films, especially polymeric thin films containing organic nanoparticles, have been proposed [1] [4]-[7]. For materials to be utilized in electrical and optical devices, it is important to ensure a thin film process, such as layer or circuit pattern, and to manipulate the size and concentration of dispersed particles to give the desired properties to the obtained materials [2]. The physical and chemical properties of such composites or hybrid materials are usually affected by the nature, size, volume fraction and shape of the dispersed particles [2].

Phthalocyanine-polymer hybrid structures are interesting from the viewpoint of synthesizing materials with given properties because of the possibility of creating metallophthalocyanines (MPcs) and fixing them in the form of clusters, associates, or crystallites in the polymer matrix [5]. The chemical, optical and electronic response of these materials is affected by the interrelation between the optical properties of a single Pc molecule and its local environment, as well as the structural arrangement of the monomer units and furthermore of the macromolecular chains [6]. Phthalocyanine films made by dispersing fine particles of pigment in a polymer binder have attracted considerable attention because of the current interest in solar energy conversion [7]. One of the methods is to obtain different polymorphic nanocrystalline modifications of MPcs ( $\mathrm{M}=\mathrm{Mg}, \mathrm{Cu}, \mathrm{Pb}, \mathrm{Ti})$ by reprecipitation followed by their introduction into a polymer solution that does not dissolve the MPc nor the solvent removal [5]. The vacuum procedure involves simultaneous laser spraying of a CuPc and polystyrene mixture followed by simultaneous deposition of the products on a substrate [5]. Other strategies consist of template-assisted growth of nanostructured porous structures for CuPc [8]. The size of MPc inclusions depends on the ratio of the components, film thickness, conditions of further thermal processing and solubility. Up to now, the phthalocyanines which have captured the attention of most scientists are metal-free phthalocyanine $\left(\mathrm{H}_{2} \mathrm{Pc}\right)$ and CuPc. MPcs (M = Fe, Co, Ni) have received considerably less attention. It is, therefore, important to seek a simple procedure for the preparation of MPc-polymer composites thin films to obtain MPc $(\mathrm{M}=\mathrm{Fe}, \mathrm{Co}, \mathrm{Ni})$ particles, uniformly distributed in the polymer matrix and having long-range order of molecular stacking. These hybrid thin films combine the properties of the polymers with the properties of MPc and provide a barrier effect because of the permeating atmospheric gas molecules [6]. In this paper, we report the preparation of nylon 11 films containing $\mathrm{M}(\mathrm{II}) \mathrm{Pc}(\mathrm{M}=\mathrm{Fe}, \mathrm{Co}, \mathrm{Ni})$ particles using a thermal relaxation technique. For the characterization of the obtained composite films, FT-IR spectroscopy, SEM, EDS, TEM and AFM were used. In this communication, we report the determination of optical parameters related to the main transitions in the UV-Vis region, as well as the corresponding fundamental energy gaps calculations for thin films. We also discuss the relation between the film microstructure and optical properties characteristic of MPc particles. These results are compared with those obtained in thin films prepared uniquely from MPcs. Finally, the electrical conductivity of the hybrid films is evaluated by means of a four-point technique.

\section{Experimental}

\subsection{Preparation of Films}

Hybrid films consisting of MPc (M = Fe, Co, Ni) particles embedded in nylon 11 matrices were prepared by the consecutive evaporation of the polymer and an MPc, and then with heat treatment. The nylon 11 matrix film was prepared onto quartz, (100) monocrystalline silicon (c-Si) substrates, and Corning 7059 glass substrates with a contact conductor of indium tin oxide (ITO) by a vapour deposition of a nylon 11 pellet using a vacuum chamber with a diffusion pump and a special tantalium crucible. All samples were obtained by using the same deposition system, with the crucible and substrates arranged in similar geometries. The pressure in the vacuum chamber before the film deposition $\left(1 \times 10^{-6}\right.$ Torr $)$ and the evaporation rate $(70 \AA / \mathrm{s})$ were the same in all cases. MPcs $(\mathrm{M}=\mathrm{Fe}, \mathrm{Co}, \mathrm{Ni})$ were then vapor deposited on the nylon 11 films at $453 \mathrm{~K}$ using tungsten crucible with a double-grid cover. The pressure in the vacuum chamber before the film deposition $\left(1 \times 10^{-5}\right.$ Torr $)$ and the evaporation rate $(16 \AA / \mathrm{s})$ were the same in all cases. The thicknesses were monitored throughout the deposition processes using a quartz crystal monitor and were subsequently checked by means of profilometry. After the vapor deposition, in order to penetrate MPc particles into nylon 11 matrix, the films were heat-treated at $393 \mathrm{~K}$ for 10 min. On the other hand, thin films deposition of MPcs (M = Fe, Co, Ni) was carried out by vacuum ther- 
mal evaporation onto quartz substrate. In order to avoid the powder products from reaching the surface of the substrate, the evaporation source was a tungsten boat with two grids. The temperature of evaporation in the boat was $473 \mathrm{~K}$, measured by means of a chromel-alumel thermocouple. The pressure in the vacuum chamber before the film deposition was $1 \times 10^{-5}$ Torr and the evaporation rate was $16 \AA /$ s.

\subsection{Thin Films Characterization}

IR spectroscopy was used to determine the presence of the most representative functional groups and whether there were significant chemical changes in the materials during the thermal evaporation process. FT-IR measurements were obtained with a Nicolet iS5-FT spectrophotometer using silicon flakes as substrate for the thin films. The distribution of dispersed particles was observed in the quartz substrate and a microanalysis was carried out using a Field Emission Gun-Scanning Electron Microscope (FEG-SEM) Auriga Carl Zeiss operating at $5 \mathrm{KV}$ and equipped with an Energy Dispersive X-Ray Spectrometry (EDS), QUANTAX, X Flash Bruker. The size and distribution of dispersed particles were observed via TEM using a Transmission Electron Microscope, TEM, JEOL JEM2010, LaB6 at 200 kV, 105 micro Amp. For TEM observation, the films were deposited directly on a carbon Type-B, 400 mesh, copper grids. AFM characterization used a JEOL microscope, model JSPM-4210, with Tapping (AFM) work mode. For AFM characterization of the films, quartz and silicon substrates were used. The optical absorption spectra of the composite films, was measured in a wavelength range of 200 - $1150 \mathrm{~nm}$ by a Unicam spectrophotometer model UV300, with a quartz substrate. Film thickness and roughness were determined by profilometry in quartz substrate in a Brukerprofilometer, model DEKTAK XT with STYLUS, LIS 3, 2 um RADIUS-Type B. The electric conductivity of the films were studied by means of a four-point probe; for these measurements, the substrates were Corning glass with a contact conductor (ITO). In order to get an ohmic contact with the deposited films, the electrodes were made of silver. The electric current was measured as a function of temperature with an applied voltage of $100 \mathrm{~V}$ in the ohmic regime, using a programmable voltage source and a Keithley 4200-SCS-PK1 autoranging picoammeter.

\section{Results and Discussion}

We have developed a process to prepare polymer films containing MPc particles by a thermal relaxation technique. The MPc/nylon 11 hybrid films were kept for $10 \mathrm{~min}$ at $393 \mathrm{~K}$, which is a temperature above the glass transition temperature (Tg) of nylon 11 (about $343 \mathrm{~K}$ ). Table 1 shows the colors of MPc/nylon 11 films before and after heat treatment. When MPc (M = Fe, Co, Ni) films were deposited on nylon 11, the MPc/nylon 11 hybrid films showed their respective color. However, after heat treatment, these colors rapidly and completely disappeared and changed into a uniform transparent blue $(\mathrm{CoPc})$, orange $(\mathrm{FePc})$ or yellow $(\mathrm{NiPc})$ due to the MPc particles dispersion [1]-[3]. The optical response of these materials was greatly affected by the interrelation between the optical properties of a MPc molecule and the structural arrangement of the monomer units [6].

After the deposit, IR spectroscopy processes were carried out to identify the chemical bonds and functional groups. The absorption bands in the spectra of the MPc/nylon 11 hybrid films and the deposited MPc films were nearly the same; differences were only attributed to the signals of nylon 11 . These results suggest that the thermal evaporation and the deposition processes do not affect the molecular structure. Figure 1 shows the signals corresponding to the Pc ring [9]: two bands appearing at about $3076 \pm 3$ and $3050 \mathrm{~cm}^{-1}$ were assigned to $\mathrm{CH}$ asymmetric and symmetric stretching vibrations in the ring. Those bands at $2933 \pm 3$ and $2807 \mathrm{~cm}^{-1}$ were assigned to $\mathrm{CH}$ symmetric and asymmetric stretching vibrations of alkyl, while the band appearing at $1117 \pm 4 \mathrm{~cm}^{-1}$ was assigned to C-H bending in plane deformations [10]. Besides, the band appearing at $910 \pm 4 \mathrm{~cm}^{-1}$ was assigned to $\mathrm{C}-\mathrm{H}$ bending out of plane deformations. The band appearing at $1614 \pm 5 \mathrm{~cm}^{-1}$ was assigned to $\mathrm{C}-\mathrm{C}$ stretching in isoindole. The band appearing at $684 \pm 4 \mathrm{~cm}^{-1}$ was assigned to C-C macrocycle ring deformation. It is note-

Table 1. Colors of MPc/nylon 11 films before and after heat treatment.

\begin{tabular}{ccc} 
Sample & Before treatment & After treatment \\
Nylon 11 & Transparent white & Transparent white \\
Co(II)Pc-nylon 11 & Blue & Transparent blue \\
Fe(II)Pc-nylon 11 & Green & Transparent orange \\
Ni(II)Pc-nylon 11 & Red & Transparent yellow \\
\hline
\end{tabular}




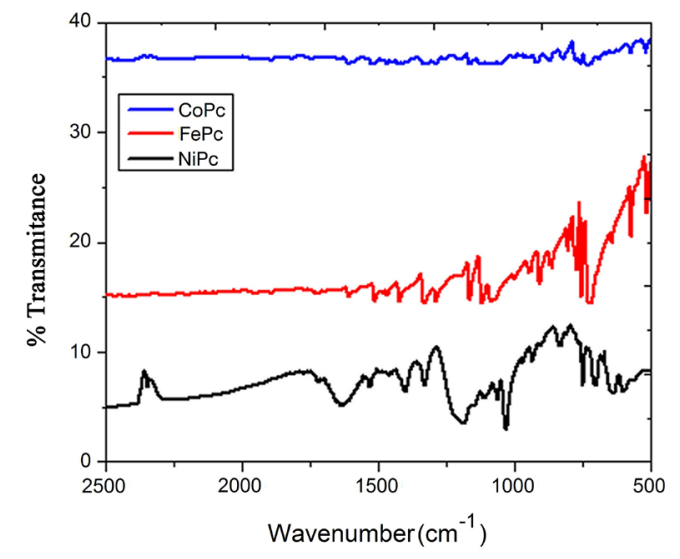

Characteristic FT-IR bands for Phthalocyanine/polymer thin films (cm-1)

\begin{tabular}{|c|c|c|c|c|}
\hline Sample & $\mathrm{v}(\mathrm{CH}) \mathrm{cm}^{-1}$ & $\mathrm{v}(\mathrm{C}-\mathrm{C}) \mathrm{cm}^{-1}$ & $\mathrm{v}(\mathrm{C}-\mathrm{N}) \mathrm{cm}^{-1}$ & $\alpha-$ form $\mathrm{cm}^{-1}$ \\
\hline $\mathrm{Fe}(\mathrm{II}) \mathrm{Pc} /$ nylon 11 & $\begin{array}{c}3076,3050,2936, \\
2807,1110,908\end{array}$ & 1617,681 & $1282,1161,1073$ & 725 \\
\hline $\mathrm{Co}(\mathrm{II}) \mathrm{Pc} /$ nylon 11 & $\begin{array}{c}3078,3050,2930 \\
2807,1122,913\end{array}$ & 1609,688 & $1286,1164,1080$ & 728 \\
\hline $\mathrm{Ni}(\mathrm{II}) \mathrm{Pc} /$ nylon 11 & $3073,2930,1118,897$ & 1616,684 & $1282,1167,1078$ & 726 \\
\hline
\end{tabular}

Figure 1. IR spectroscopy for MPc-Nylon 11 films.

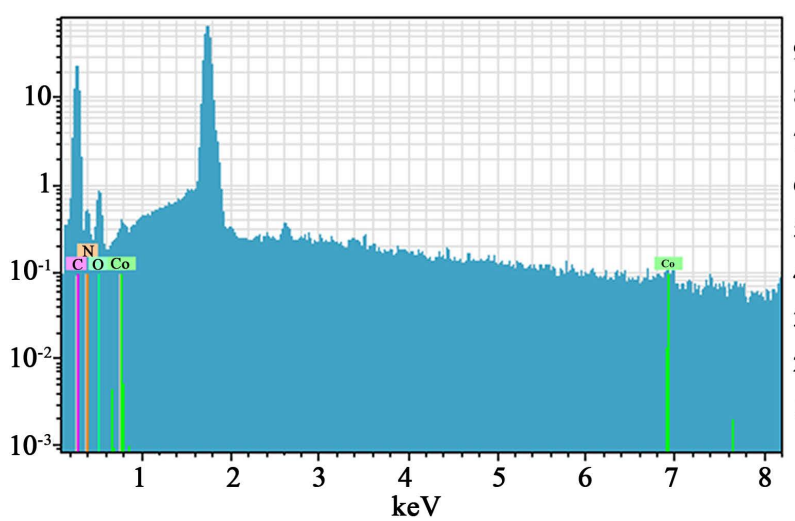

(a)

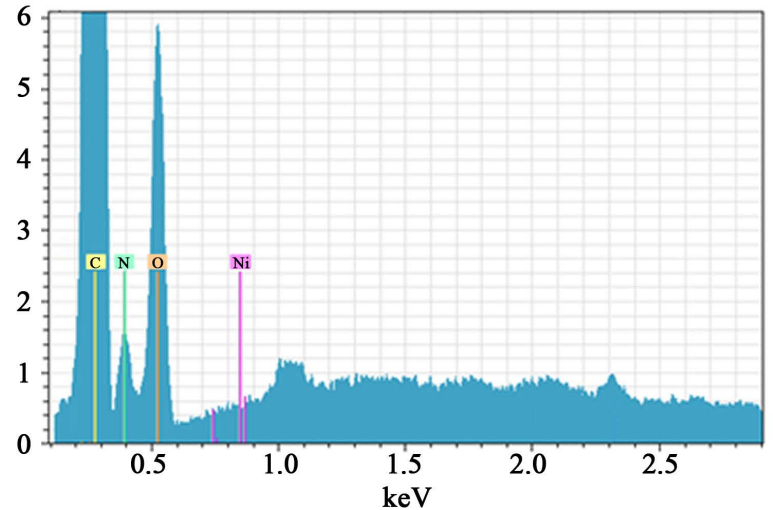

(c)

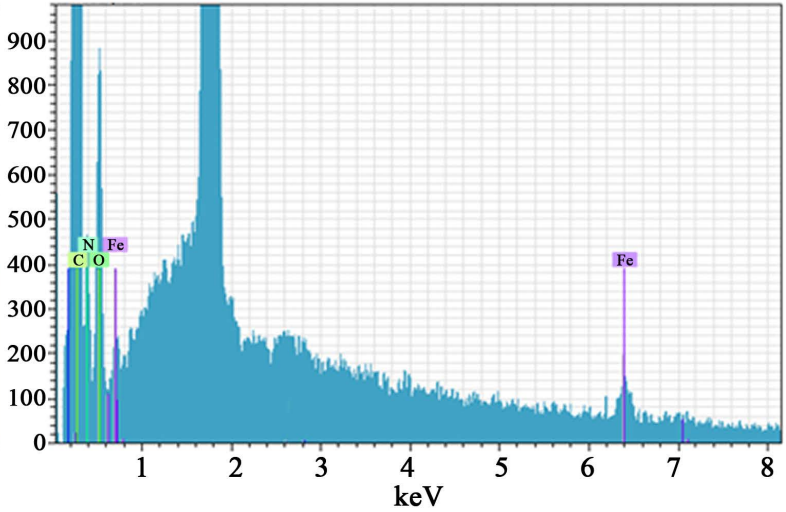

(b)

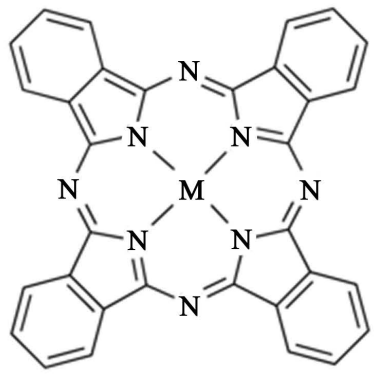

Figure 2. EDS for MPc-nylon 11 films (a) CoPc; (b) FePc; and (c) NiPc.

worthy to observe the bands appearing at $1284 \pm 2,1164 \pm 3$ and $1077 \pm 4 \mathrm{~cm}^{-1}$, which were assigned to C-N in isoindole, in plane band, and in pyrrole stretching vibration, respectively [10]. An EDS analysis was performed to determine the chemical composition of the thin films. The MPc chemical structure is shown below Figure 2. Figures 2(a)-(c) show the EDS spectrum for MPc/nylon 11 hybrid films, where the presence of the reference elements for all species is observed.

Additionally, MPcs are known to have different polyforms which can clearly be identified by IR absorption technique [11] [12]. The spectral characteristics distinguishing the different MPc crystalline forms are between $800 \mathrm{~cm}^{-1}$ and $700 \mathrm{~cm}^{-1}$. These differences are attributed to the different ways in which molecules arrange them- 
selves, especially for those forms around $777 \mathrm{~cm}^{-1}$, which correspond to the $\beta$ form and those forms around 720 $\mathrm{cm}^{-1}$ correspond to the $\alpha$ form [11] [13]. From these studies, we are able to determine the phase and any significant chemical changes which may have occurred in these materials during the thermal evaporation and after heat treatment. Initially, when the spectra of the MPcs deposited in the nylon 11 were analyzed, an $\alpha$ and $\beta$ forms were observed with the values of $720 \mathrm{~cm}^{-1}$ and $777 \mathrm{~cm}^{-1}$, respectively. After the thermal relaxation, none of the $\beta$ forms were observed, but the $\alpha$ form remained in $726 \pm 2 \mathrm{~cm}^{-1}$ (see table in Figure 1). These results show how the MPc structure changed due to heat treatment [3]. Throughout the thermal relaxation process, for which a heating and a slow cooling took place, an additional growth into an $\alpha$ form may be observed. The thermal relaxation process may be considered as related to the intramolecular forces in connection with both, the crystalline structure and a two-stage action of nucleation and; a two-stage action of nucleation and growth taking effect.

The morphology of MPc/nylon 11 hybrid films was studied by SEM and TEM. SEM images of the MPc/nylon 11 films are shown in Figures 3(a)-(d). In the SEM, the contrast between the two phases of the composite can be observed. Both nylon 11 fibers and the presence of spherical MPc particles can be observed. It was found that the MPc particles were homogeneously dispersed in the surface of the film.

Figure 4 shows TEM images of MPc films. It was found that the CoPc particles were dispersed in the matrix (4(b)-(c)). The crystalline character of the MPc particles (4(d)-(f)) could be observed owing to the amorphous nature of the nylon 11 matrix (4a). The nylon 11 matrix can behave as a viscous fluid giving mobility to the MPc particles, which may allow a coalescence of the particles [2]. Individual MPc particles in the films were however, well isolated after the treatment. This isolation could be attributed to the strong interaction between MPc particles and nylon molecules [1]-[3]. The dispersed MPc particles are stable with no aggregation or coalescence occurring over five months under air. The mechanism of particle dispersion caused by thermal relaxation is proposed as follows (according with Akamatsu, Noguchi, et al. for metallic particles) [1]-[3]: because the nylon 11 thin films on the substrate are rapidly fixed from the gaseous state to the solid state during the vapor deposition process, these films possess a thermodynamically metastable structure which can relax to a much more stable structure upon heat treatment [1]-[3]. The MPc is deposited on this polymer film before the polymer film relaxes. With the effect of the thermally-induced structural relaxation, a composite thin film is obtained, in which the MPc particles ranging between 1 to $10 \mathrm{~nm}$ are uniformly dispersed and stably fixed with nylon molecules.

Figure 5 shows the images of MPc/nylon 11 hybrid films obtained with an AFM in order to provide a surface inspection of the micro-structural arrays. Owing to the fact that the conditions for deposition and heat treatment

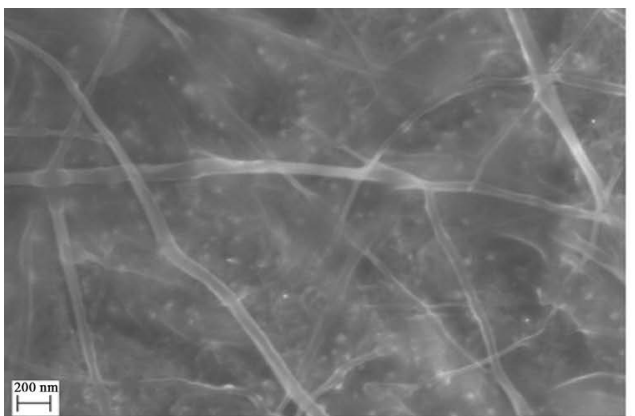

(a)

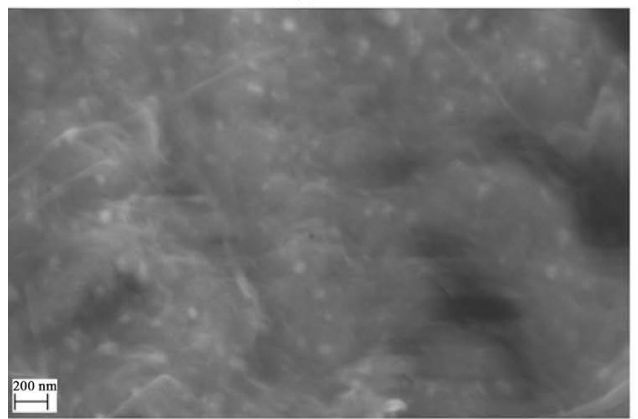

(c)

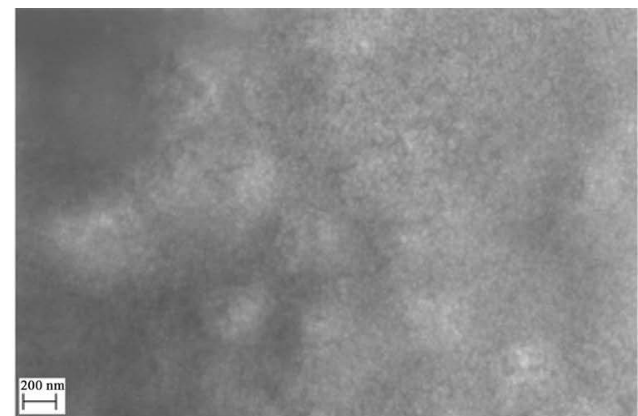

(b)

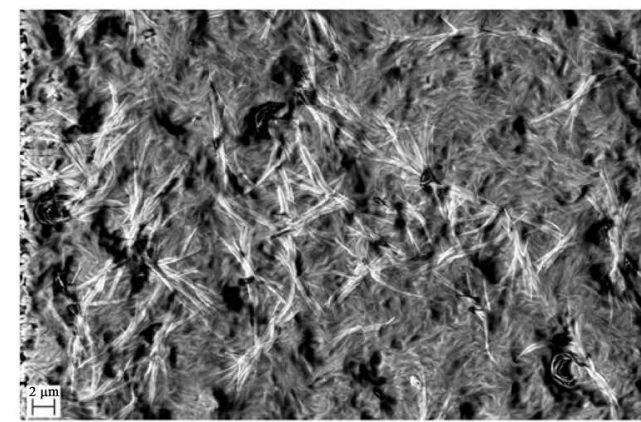

(d)

Figure 3. SEM image of MPc/nylon 11 films (a) CoPc; (b) FePc; (c) NiPc; and (d) nylon 11. 


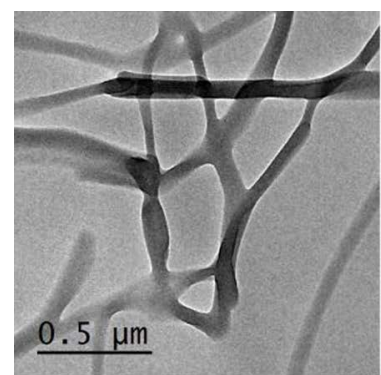

(a)

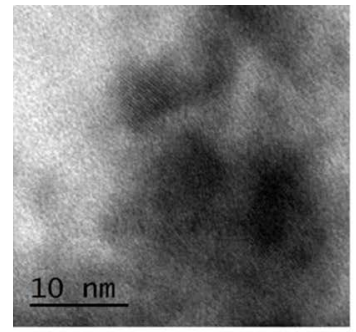

(d)

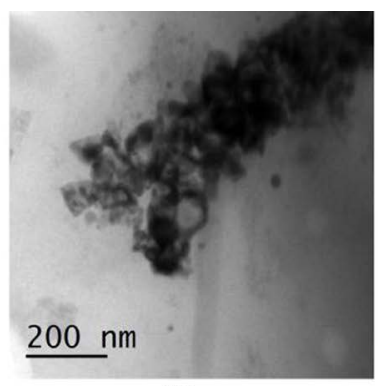

(b)

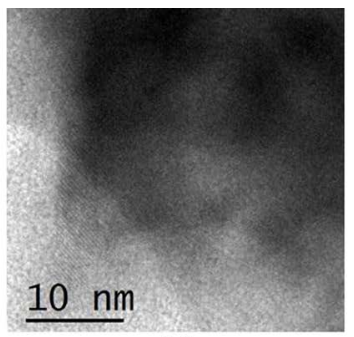

(e)

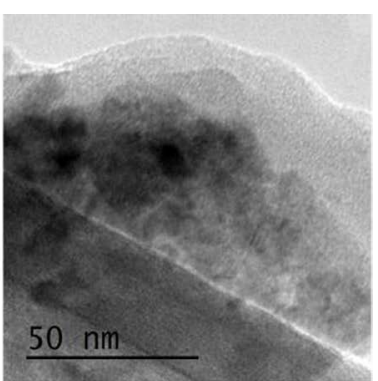

(c)

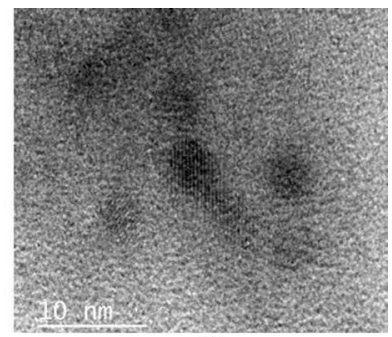

(f)

Figure 4. TEM micrographs of MPc/nylon 11 films (a) nylon 11 matrix; (b)-(d) CoPc/nylon 11; (e) NiPc/nylon 11; and (f) FePc/nylon 11 films.

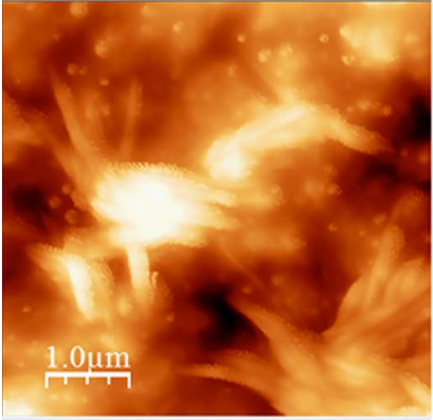

(a)

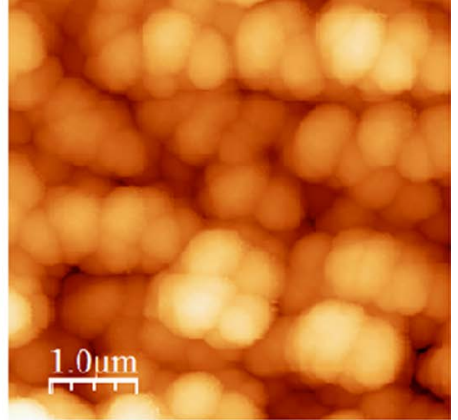

(b)

Figure 5. AFM images of nylon 11 films containing (a) CoPc and (b) FePc. Scan size is $5 \mu \mathrm{m}$.

were the same for both film samples, the difference in the morphology and roughness values may be related to the different MPcs in each hybrid film. MPc/nylon 11 (M = Fe, Co, Ni) showed different morphology domains in which the forms, sizes, arrangement, orientation and distribution were related to the molecular structure [14]. Grain size and distribution were homogenously formed in FePc/nylon 11 compact deposits (Figure 5(b)). However for CoPc/nylon 11 (Figure 5(a)) and NiPc/nylon 11, nylon 11 fibers were cleaved transversely and exhibit a topography with an elevated roughness which is not possible to be determined directly from AFM measurements. Collectively, AFM and profilometry can provide an accurate structure for MPc/nylon 11 films. Table 2 shows the calculated RMS roughness for the hybrid films. The compound with CoPc presented the lowest roughness while film with NiPc presented the highest. The FePc and NiPc seem to have been more affected than CoPc by the thermal gradient occurring between the room-temperature substrate and the high-temperature evaporated material. The CoPc nucleated upon the substrate and and then this substrate was completely covered during the sublimation process. IR spectroscopy results suggest that the compounds did not undergo chemical decomposition (see Figure 1) and had similar deposition rates. Nevertheless, they showed that-as films-morphological differences depend directly on the metallic atom in the Pc molecule and on the electrostatic forces occurring during deposition. Table 2 shows thickness values for all MPc/nylon 11 films. It is worth noting that the most heterogeneous deposition, as well as the roughest thin film, corresponds to the NiPc molecule.

Optical absorption measurements are widely used to characterize the electronic properties of MPc/nylon 11 films through the determination of parameters describing electronic transitions, such as band gap, valence band 
tails and excited state lifetime [15]. UV-Vis spectra for MPcs originate from the molecular orbitals within the $18-\pi$ electron system and from the overlapping orbitals on the central metal atom. Phthalocyanines have two typical absorption bands, namely the Q band in the visible region $(530-800 \mathrm{~nm})$ and the B or Soret band in the near-ultraviolet region (300 - $400 \mathrm{~nm}$ ) [11] [16]-[19]. Figure 6(a) shows optical absorption spectra of the films. The UV-Vis spectra of CoPc/nylon 11 and FePc/nylon 11 exhibited the characteristic Q band at 609 and $663 \mathrm{~nm}$, respectively. The phenomenon is attributed to the $\pi \rightarrow \pi^{*}$ transition from the highest occupied molecular orbital (HOMO) to the lowest unoccupied molecular orbital (LUMO) of the $\mathrm{pc}^{2-}$ ring. The B band was exhibited in the UV region at $320 \mathrm{~nm}$ for CoPc/nylon 11 arising from the deeper $\pi$ levels $\rightarrow$ LUMO transition. The B band for the composite FePc/nylon 11 and the two bands: Q and B for the composite NiPc/nylon do not appear in the spectrum. Apparently, the presence of the polymeric matrix interferes with the electronic transport that normally occurs between the MPc molecules. However, MPc/nylon 11 (M = Fe, Co) films absorb light from either side of the blue-green region and can be used as photoconductive materials and color filters [19]. The changes in the $\mathrm{UV}$-Vis spectra are due to the contributions of the central elements in the Pc ring to the molecular orbitals in this region.

The optical band gap was determined from the analysis of the spectral dependence of the absorption near the fundamental absorption edges. Evaluation of the absorption coefficient $\alpha$ is defined by the Lambert-Beer law and can be calculated from the optical transmittance [20] [21]. The absorption coefficient $\alpha$ in many amorphous semiconductors shows an exponential dependence on photon energy usually obeying the empirical relation [21]-[23]:

$$
\alpha h v=\beta\left(h v-E_{g}\right)^{n}
$$

The factor $\beta$ depends on the transition probability and can be assumed to be constant within the optical frequency range and $n$ is a number characterizing the transition process. In amorphous semiconductors, the optical transitions are dominated by the so-called indirect interband transitions [11]. The indirect electronic transitions seem to be of the $\pi$ to $\pi^{*}$ type. In these electronic transitions, occurring from states of the valence band to states of the conduction band, there is no conservation of the electronic momentum [24]. For allowed indirect transitions, $n=$ 2. Thus, the optical gaps Egi could be determined from the extrapolation to zero of the linear region of the $(\alpha / h v)^{1 / 2}=f(h v)$ curve [11]. Figure 6(b) shows the dependence of the absorption coefficient on photon energy and the optical gap determination is shown in Table 2. Similar values are found for MPc/nylon $11(\mathrm{M}=$ $\mathrm{Fe}, \mathrm{Co}$ ); nevertheless, from this table it is clear that the optical band gap increases with the number of electrons in the $3 \mathrm{~d}$ orbitals for the divalent cations $\mathrm{Fe}^{2+}$ and $\mathrm{Co}^{2+}$. The divalent cation $\mathrm{Ni}^{2+}$ exhibits a small response in the $\mathrm{UV}$-vis spectra, which is probably due to the fact that the $3 \mathrm{~d}$ orbital in this cation is almost full and thus provides evidence of the electrostatic nature of the coordinated process in these complexes. Similar results were obtained by Seoudi et al. for different MPcs [19], which established that the optical band gap changes according to the number of electrons in the outer shell of the metallic cation [19]. On the other hand, for the FePc and CoPc molecules, it is not considered a dependence between the band gap and the size of the dispersed particles. The band gap was obtained for thin films of the studied MPc and the obtained values are similar to those found in the MPc/nylon $11(\mathrm{M}=\mathrm{Fe}, \mathrm{Co})$ laminated films. This may be due to the fact that the size distribution was relatively large and the nylon 11 does not seem to influence electronic transport between the valence and conduction bands of these compounds. The metallic center in Pc molecules is the one responsible for conductivity.

In order to investigate the electrical transport properties of the hybrid thin films, the variation of electrical conductivity with temperature in thin films was evaluated by using the four-probe method. The measurement took place over a line on the material that had equal spaces between the test points. Care was taken to ensure that the current involved was low enough to prevent sample heating and the voltmeter had high input impedance. Electrical measurements showed an insulating character for the thin films. Apparently, the low conductivity of the polymer matrix influences the material. With increasing temperature, the semiconductivity of phthalocyanine particles, is not sufficient to enhance the electrical nature of the material. From the above results, the electrical conductivity of all thin films was evaluated at $298 \mathrm{~K}$. Table 2 shows the calculated values of electrical conductivity $\sigma$ at $298 \mathrm{~K}$ for all studied MPc/nylon 11 and the CoPc/nylon 11 thin film shows a higher electrical conductivity. For MPc/nylon $11(\mathrm{M}=\mathrm{Co}, \mathrm{Fe})$ these $\sigma$ values are within the semiconductor region $\left(10^{-6}\right.$ to $10^{2}$ $\mathrm{S} / \mathrm{cm}$ ) for organic materials [25] [26]. The large and homogeneous distribution of MPc (M = Fe, Co) particles in the thin films favored the charge transfer mechanism. NiPc/nylon 11 does not show an acceptable electrical conductivity, related to the electronic configuration of the metallic atom in the phthalocyanine, the high rugosity 


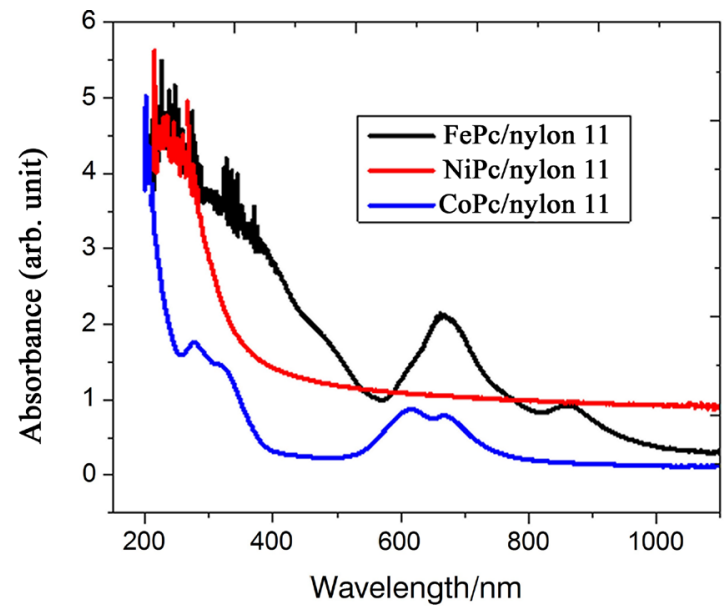

(a)

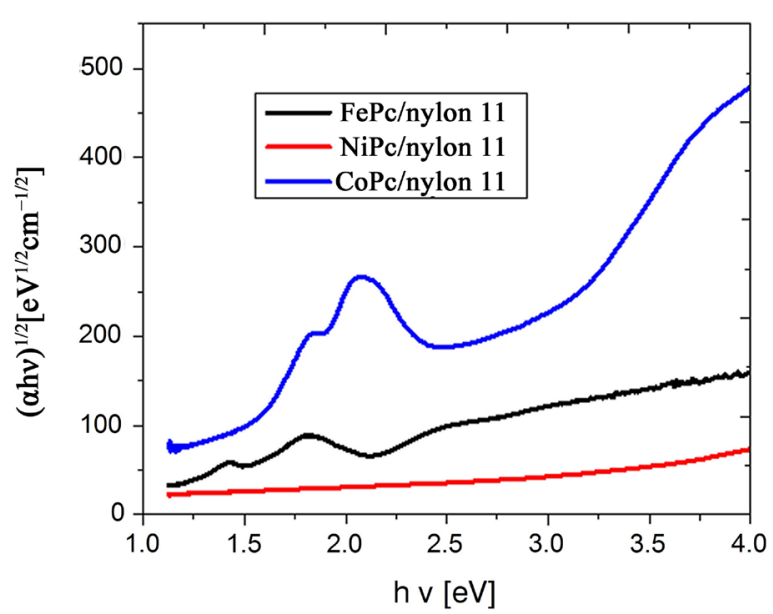

(b)

Figure 6. (a) Optical absorption spectra and (b) Plot of $(\alpha / h v)^{1 / 2}$ vs. photon energy $h v$ of the MPc $(\mathrm{M}=\mathrm{Fe}, \mathrm{Co}, \mathrm{Ni}) \mathrm{par}-$ ticles dispersed in nylon 11 films.

Table 2. Characteristic parameters of the MPc/nylon 11 hybrid films.

\begin{tabular}{cccccc}
\hline Sample & $\begin{array}{c}\text { RMS } \\
\text { roughness } \\
(\mathrm{nm})\end{array}$ & $\begin{array}{c}\text { Film thickness } \\
(\mathrm{nm})\end{array}$ & $\begin{array}{c}\text { Indirect optical } \\
\text { activation energy (eV) } \\
\text { M(II)Pc/nylon 11 hybrid films }\end{array}$ & $\begin{array}{c}\text { Indirect optical } \\
\text { activation energy (eV) } \\
\text { M(II)Pc films }\end{array}$ & $\begin{array}{c}\text { Electrical } \\
\text { conductivity } \\
(\mathrm{S} / \mathrm{cm})\end{array}$ \\
\hline Fe(II)Pc/nylon 11 & 450 & 550 & 1.5 & 1.2 & $5.8 \mathrm{E}-5$ \\
Co(II)Pc/nylon 11 & 2970 & 11,873 & 1.1 & 1.7 & $1.38 \mathrm{E}-6$ \\
Ni(II)Pc/nylon 11 & 29,530 & 50,125 & 2.6 & 2.7 & $4.01 \mathrm{E}-7$ \\
\hline
\end{tabular}

conditions and the deposits thickness. The orbital configuration of the central metal ion in Pcs must be considered, as it provides the block conduction through regions of a molecule. The Fe(II) $d^{6}$ and Co(II) $d^{7}$ systems have a significant $d$ orbital character near the Fermi energy while the $\mathrm{Ni}$ (II) $\mathrm{d}^{8}$ does not. This interpretation is consistent with theoretical calculations that predict a large contribution of iron and cobalt $d$ orbitals near the Fermi energy [27]. The presence of local orbitals close to the Fermi energy produces large conduction as local HOMOs and LUMOs far from the Fermi energy result in insulating behavior [27]. On the other hand, in ordinary semiconductors, conductivity is also related to impurity types, their location and concentration, crystal structure, stacking and orbital overlap. Holes in the valence band and electrons in the conduction band contribute to the electrical conductivity. In these semiconducting films, there are two stages describing the movement of carriers within the samples. If there are orbitals existing with the same energy levels, the electrons can jump from one atomic site to another in the intramolecularMPc transfer of electrons. In the case of intermolecular orbital overlap, electrons or holes can travel from one kind of MPc molecule to another. From these results, MPc/nylon 11 (M = Fe, Co) films may be suitable for photovoltaic applications [28] [29].

\section{Conclusion}

Nylon 11 films containing MPc (M = Fe, Co, Ni) particles have been reproducibly prepared by using a thermal relaxation technique. After heat treatment, the MPc particles are uniformly dispersed in the matrix and are well isolated, owing to the strong interaction between MPc particles and nylon molecules. Thus, a method for the preparation of MPc/nylon 11 hybrid films has been developed, which may be related to the different MPcs in each film. The optical absorption spectrum is used to parameterize the photon energy dependence of the extinction coefficient. The band gap energy of MPc/nylon 11 hybrid films is almost equal the MPc films value. Concerning the electrical conduction in the thin films, the use of the MPc (M = Fe, Co, Ni) and nylon 11 in the preparation of composite thin films leads to conductivity values lower than those for intrinsic semiconductors but rather higher than those for the most common insulators, as corresponds to band gaps in the $3-4 \mathrm{eV}$ range. 
The MPc/nylon 11 (M = Fe, Co) films show electrical conductivities at room temperature of the order of $10^{-6}$ $(\mathrm{S} / \mathrm{cm})$, which appear to show a semiconducting behavior. Electron transport in these materials is strongly influenced by the metal in the phthalocyanine. On the basis of the optical band-gap, electrical conductivity values and the feasibility of preparing these compounds as hybrid films, it is suggested to use these MPc/nylon 11 films $(\mathrm{M}=\mathrm{Fe}, \mathrm{Co})$ in electronic device fabrication.

\section{Acknowledgements}

The authors wish to thank the technical support of Ing. Guillermo Villagran in the Anáhuac University and MSc. Álvaro Ángeles Pascual in the FEG-SEM at the Advanced Laboratory for Electron Nanoscopy of the Center for Research and Advanced Studies (LANE-CINVESTAV). M.E. Sánchez-Vergara gratefully acknowledges the financial support of the Secretariat of Public Education-National Council on Science and Technology-Mexico (SEP-CONACYT-México) under project number 153,751.

\section{References}

[1] Akamatsu, K., Takei, S., Mizuhata, M., Kajinami, A., Deki, S., Takeoka, S., Fujii, M., Hayasthi, S. and Yamamoto, K. (2000) Preparation and Characterization of Polymer Thin Films Containing Silver and Silver Sulfide Nanoparticles. Thin Solid Films, 359, 55-60. http://dx.doi.org/10.1016/S0040-6090(99)00684-7

[2] Akamatsu, K. and Deki, S. (1997) Characterization and Optical Properties of Gold Nanoparticles Dispersed in Nylon 11 Thin Films. Journal of Materials Chemistry, 7, 1773-1777. http://dx.doi.org/10.1039/a703055j

[3] Noguchi, T., Gotoh, K. and Yamaguchi, Y. (1991) Novel Method to Disperse Ultrafine Metal Particles into Polymer. Journal of Material Science Letters, 10, 477-479. http://dx.doi.org/10.1007/BF00838357

[4] Nitschke, C., O’Flaherty, S.M., Kroell, M., Strevens, A., Maier, S., Rüther, M.G. and Blau, W.J. (2003) Organic Photonic Materials and Devices. Proceedings of SPIE, 4991, 124-132. http://dx.doi.org/10.1117/12.475443

[5] Lbova, A.K., Vasiliev, M.P. and Gutmann, E.S. (2011) Phthalocyanine and Polystyrene Film Nanocomposites. Russian Journal of Physical Chemistry A, 85, 457-461. http://dx.doi.org/10.1134/S0036024411030216

[6] Logothetidis, S. (2008) Flexible Organic Electronic Devices: Materials, Process and Applications. Materials Science and Engineering B, 152, 96-104. http://dx.doi.org/10.1016/j.mseb.2008.06.009

[7] Abdel-Malik, T.G., Abdel-Latif, R.M., El-Samahy, A.E. and Khalil, S.M. (1995) Phthalocyanine and Polystyrene Film Nanocomposites. Thin Solid Films, 256, 139-142. http://dx.doi.org/10.1016/0040-6090(94)06319-2

[8] Berhanu, S., Tariq, F., Jones, T. and McComb, D.W. (2010) Three-Dimensionally Interconnected Organic Nanocomposite Thin Films: Implications for Donor-Acceptor Photovoltaic Applications. Journal of Materials Chemistry, 20, 8005-8009. http://dx.doi.org/10.1039/c0jm01030h

[9] Seoudi, R., El-Bahy, G.S. and El Sayed, Z.A. (2005) FTIR, TGA and DC Electrical Conductivity Studies of Phthalocyanine and Its Complexes. Journal of Molecular Structure, 753, 119-126. http://dx.doi.org/10.1016/j.molstruc.2005.06.003

[10] Hart, M.M. (2009) Cationic Exchange Reactions Involving Dilithium Phthalocyanine. Thesis for the Degree of Master of Science, Wright State University, Dayton.

[11] El-Nahass, M.M., Abd-El-Rahman, K.F., Al-Ghamdi, A.A. and Asiri, A.M. (2004) Optical Properties of Thermally Evaporated Tin-Phthalocyanine Dichloride Thin Films, SnPcCl 2 . Physica B, 334, 398-406. http://dx.doi.org/10.1016/j.physb.2003.10.019

[12] Robinet, S., Clarisse, C., Gauneau, M. and Salvi, M. (1989) Spectroscopic and Structural Studies of Scandium Diphthalocyanine Films. Thin Solid Films, 182, 307-317. http://dx.doi.org/10.1016/0040-6090(89)90267-8

[13] El-Nahass, M.M., Farag, A.M., Abd-El-Rahman, M.M. and Darwish, A.A.A. (2005) Dispersion Studies and Electronic Transitions in Nickel Phthalocyanine Thin Films. Optics \& Laser Technology, 37, 513-523. http://dx.doi.org/10.1016/j.optlastec.2004.08.016

[14] Zhang, Q., Huang, D.Y. and Liu, Y.G. (2003) Preparation of Langmuir-Blodget Films of Phthalocyanines and Investigation by Atomic Force Microscope. Synthetic Metals, 137, 989-990. http://dx.doi.org/10.1016/S0379-6779(02)01064-0

[15] Laidani, N., Bartali, R., Gottardi, G., Anderle, M. and Cheyssac, P. (2008) Optical Absorption Parameters of Amorphous Carbon Films from Forouhi-Bloomer and Tauc-Lorentz Models: A Comparative Study. Journal of Physics: Condensed Matter, 20, Article ID: 015216. http://dx.doi.org/10.1088/0953-8984/20/01/015216

[16] El-Nahass, M.M., Sallam, M.M. and Ali, H.A. (2005) Optical Properties of Thermally Evaporated Metal-Free Phthalocyanine $\left(\mathrm{H}_{2} \mathrm{Pc}\right)$ Thin Films. International Journal of Modern Physics B, 19, 4057-4071. 
http://dx.doi.org/10.1142/S0217979205032632

[17] El-Nahass, M.M., Abd-El-Rahman, K.F. and Darwish, A.A.A. (2005) Fourier-Transform Infrared and UV-Vis Spectroscopes of Nickel Phthalocyanine Thin Films. Materials Chemistry and Physics, 92, 185-189. http://dx.doi.org/10.1016/j.matchemphys.2005.01.008

[18] Rajesh, K.R. and Menon, C.S. (2005) D.C. Electrical and Optical Properties of Vacuum-Deposited Organic Semiconductor FePcCl Thin Films. Canadian Journal of Physics, 83, 1151-1159. http://dx.doi.org/10.1139/p05-065

[19] Seoudi, R., El-Bahy, G.S. and El-Sayed, Z.A. (2006) Ultraviolet and Visible Spectroscopic Studies of Phthalocyanine and Its Complexes Thin Films. Optical Materials, 29, 304-312. http://dx.doi.org/10.1016/j.optmat.2005.10.002

[20] Leontie, L., Roman, M., Brinza, F., Podaru, C. and Rusu, G.I. (2003) Electrical and Optical Properties of Some New Synthesized Ylides in Thin Films. Synthetic Metals, 138, 157-163. http://dx.doi.org/10.1016/S0379-6779(02)01277-8

[21] Rodríguez-Gómez, A., Sánchez-Hernández, C.M., Fleitman-Levin, I., Arenas-Alatorre, J., Alonso-Huitrón, J.C. and Sánchez Vergara, M.E. (2014) Optical Absorption and Visible Photoluminescence from Thin Films of Silicon Phthalocyanine Derivatives. Materials, 7, 6585-6603. http://dx.doi.org/10.3390/ma7096585

[22] O’Leary, S.K. and Lim, P.K. (1997) On Determining the Optical Gap Associated with an Amorphous Semiconductor: A Generalization of the Tauc Model. Solid State Communications, 104, 17-21. http://dx.doi.org/10.1016/S0038-1098(97)00268-8

[23] Mok, T.M. and O’Leary, S.K. (2007) The Dependence of the Tauc and Cody Optical Gaps Associated with Hydrogenated Amorphous Silicon on the Film Thickness: $\alpha$ l Experimental Limitations and the Impact of Curvature in the Tauc and Cody Plots. Journal of Applied Physics, 102, Article ID: 113525. http://dx.doi.org/10.1063/1.2817822

[24] Adachi, S. (1999) Optical Properties of Crystalline and Amorphous Semiconductors. Kluwer Academic Publishers, Boston. http://dx.doi.org/10.1007/978-1-4615-5241-3

[25] Kiani, M.S. and Mitchell, G.R. (1992) Structure Property Relationships in Electrically Conducting Copolymers Formed from Pyrrole and $N$-methyl Pyrrole. Synthetic Metals, 46, 293-306. http://dx.doi.org/10.1016/0379-6779(92)90355-M

[26] Kumnar Mahapatro, A. and Ghosh, S. (2007) Charge Carrier Transport in Metal Phthalocyanine Based Disordered Thin Films. Journal of Applied Physics, 101, Article ID: 034318. http://dx.doi.org/10.1063/1.2434946

[27] Lu, X. and Hipps, K.W. (1997) Scanning Tunneling Microscopy of Metal Phthalocyanines: $\mathrm{d}^{6}$ and $\mathrm{d}^{8}$ Cases. Journal of Physical Chemistry B, 101, 5391-5396. http://dx.doi.org/10.1021/jp9707448

[28] Thakur, A., Singh, G., Saini, G.S.S., Goyal, N. and Tripathi, S.K. (2007) Optical Properties of Amorphous $\mathrm{Ge}_{20} \mathrm{Se}_{80}$ and $\mathrm{Ag}_{6}\left(\mathrm{Ge}_{0.20} \mathrm{Se}_{0.80}\right)_{94}$ Thin Films. Optical Materials, 30, 565-570. http://dx.doi.org/10.1016/j.optmat.2006.12.013

[29] Metz, J. and Hanack, M. (1983) Synthesis, Characterization, and Conductivity of ( $\mu$-Cyano)(phthalocyaninato)cobalt(III). Journal of the American Chemical Society, 105, 828-830. http://dx.doi.org/10.1021/ja00342a030 